\title{
Assessment of morbidity and mortality factors affecting geriatric trauma: A comprehensive cross-sectional study in Central India
}

Kamatham Aashish

Assistant Professor, Department of General Surgery, Government Medical College, Nagpur, Maharashtra, India

Corresponding Author: Dr. Kamatham Aashish, Assistant Professor, Department of General Surgery, Government Medical College, Nagpur, Maharashtra, India. Dr. Sanjay S Changole Associate Professor, Department of General Surgery, Government Medical College, Nagpur, Maharashtra, India.

Received Date: October 22, 2020; Accepted Date: November 11, 2020; Published Date; January $02,2021$.

Citation: Paul T E Cusack Multiple Sclerosis J. Surgi Case Rep and Imag. 4(1). Doi: 10.31579/2690-1897/050

Copyright: () 2021 Paul T E Cusack, This is an open-access article distributed under the terms of the Creative Commons Attribution License, which permits unrestricted use, distribution, and reproduction in any medium, provided the original author and source are credited.

\begin{abstract}
India is the second-most populous country in the world has about 76.6 million people at or over the age of 60 , constituting above $7.7 \%$ of total population. A cross-sectional study of 300 cases of geriatric and non-geriatric population groups was conducted at well-established Trauma, Orthopaedic and Neurosurgical services centre in Central India. Mechanisms of injury sustained by the participants showed that Falls which include both Ground level falls (GLF) and Fall from height ( $>2$ metres) contributed to $55.4 \%$ cases in the geriatric population. The next most common cause of trauma in the geriatric population was road traffic accidents amounting to $34.3 \%$ of the cases. Data on the injuries sustained by both the study cohorts in terms of the different body regions based on Abbreviated Injury Scale (AIS) and Injury severity score (ISS) showed the head region was most consistently and maximally injured in both the study populations. Comorbidity profiles of geriatric and non-geriatric trauma populations showed significantly high hypertension, cerebrovascular disease, diabetes, diminished hearing and vision among the geriatric group. The maximum number of geriatric patients underwent Orthopaedic and spine surgeries (44.9\%), Intercostal drain placements $(34.6 \%)$, while the non-geriatric population had a higher number of Craniotomies $(40 \%)$ and Intercostal drain placement (33.5\%) surgeries respectively. The geriatric population had a significantly higher crude mortality rate of 39.3\% compared to the non-geriatric population ( $26.3 \%$ ). With reference to intervention procedures, the geriatric population had a lower percentage of operative intervention and a higher rate of conservative management as compared to the non-geriatric population.
\end{abstract}

Keywords: Trauma, geriatric patients, road traffic accidents, Injury severity score, mortality

\section{Introduction}

Worldwide people are living longer with increased life expectancy. In the world's population, the aged and older population of age 60 years and above is expected to cross over by 2.1 billion by 2050 . According to the WHO, $80 \%$ of all older people will live in low- and middle-income countries by 2050 [1] According to the State of World Population 2019 report by the United Nations Population Fund (UNFPA), released last week, India's population in 2019 stood at 1.36 billion, growing from 942.2 million in 1994 and six percent of India's population was of the age 65 and above [2]. Currently, patients older than 65 years account for $23 \%$ of all trauma admissions, and trauma represents the fifth leading cause of death in this population. In view of the high prevalence of multiple comorbidities in the elderly, there is an increased likelihood of death or severe disability following trauma $[3,4,5]$. The risk of death after trauma is significantly increased in patients older than 65 years of age, and for those over the age of 80 , it is approximately four-fold that of younger patients. Further, the economic costs, as well as the societal cost are higher following trauma to elderly patients. Thus, the social and economic implications are expected to increase in geriatric trauma and clinicians must continue to strive toward a more standardized and evidence-based approach to the diagnosis and treatment of these patients.
The effect of age as a predictor of mortality in older adult trauma is difficult to assess from the existing published literature. Traditional trauma protocols have been established and proven in the treatment of younger accident victims. Older people with diminished physiological reserve, often in association with significant co-morbidities, require special consideration. The distribution of injuries and the type of injury mechanism is likely to be different in a population with a high incidence of osteoporosis [6]. Older patients can become multiply injured following low energy trauma and these injuries may have worse outcomes [7]. Patients with limited mental or physical capacity are more likely to be involved in accidents as they are slower to identify and respond to dangerous situations. Medical emergencies such as myocardial infarction or stroke precipitating an accident, making it necessary to treat this pathology alongside the patient's injuries. Mental and physical incapacity can make an assessment of these patients troublesome. Older patients may become confused and uncooperative during comparatively minor physiological derangements, often compromising their investigation or treatment $[8,9]$. For these reasons, it is important to accurately document the pattern of injuries and clinical course of older patients with severe injuries. Recent reports of polytrauma in older adults are limited and the subject has previously been given only brief attention. This study aims to 
identify and characterize the geriatric population with poly-trauma and compare them to non-geriatric trauma patients in terms of severity of injuries, patterns of injury patterns, mortality and comorbidities trauma exposed to various mechanisms of injury and trauma.

\subsection{Material and methods}

\subsection{Study Setting}

The study was conducted at a tertiary and well-established trauma care centre in Central India with Orthopaedic care, Trauma and Neurosurgical services. It is a well established hospital in these three specialties.

\subsection{Study population}

All geriatric and non-geriatric patients who had been admitted in the Trauma Care Centre through emergency medical services from June 2017- November 2019, who met the inclusion criteria were monitored in the trauma care centre until death/discharge in the wards were included in this study.

\subsection{Inclusion criteria}

Patients consenting to participate. Adult trauma patients from ages $18-$ 64 years were admitted to the Surgical Casualty and Trauma Care Centre. Adult trauma patients from ages $65-89$ years were admitted to the Surgical Casualty and Trauma Care Centre.

\subsection{Exclusion criteria}

Patients with penetrating traumatic injuries - gunshot and stab wounds. Patients below 18 years and above 90 years.

\subsection{Sample size}

The sample size is calculated as: Power (1-beta)\%: 80\%; Alpha error \%: 5. Minimum sample required in each group $n=116$ (Geriatric and Nongeriatric)

\subsection{Estimated final sample size}

300 cases each in both geriatric and non-geriatric population groups were enrolled in this study in accordance with the inclusion criteria.

\subsection{Sampling Method}

Study participants were drawn from all the patients who were admitted to the tertiary trauma centres of central India from June 2017 to November 2019. All adult trauma admissions from ages (18 -89 years) were subjected to the pre-determined inclusion criteria. Participants were then subsequently divided into two cohorts from all eligible adult trauma patients - the first consisting of a control group of all patients ages 18 to 64 years (non-geriatric patients) and the second consisting of all patients ages 65 to 89 years (geriatric patients). The included study subjects were then examined in accordance with the various parameters included in the proforma below.

\subsection{Variables collected for each group were}

- Admission demographics.

- Vital signs and physiological parameters on admission.

- Mechanism of injury subdivided into falls (with a subgroup of ground level falls and falls from height ( $<2$ meters), Road Traffic accidents, Assaults and others.

- Injury Severity Score (ISS)

- Abbreviated Injury Scale (AIS) for each body region.

- Comorbidities including Hypertension, Ischemic heart disease, Diabetes mellitus, Chronic obstructive pulmonary disease, Cerebrovascular disease, Chronic renal failure, diminution of vision and hearing were considered.
- Interventional procedures afforded to both the population groups in terms of surgical procedures or conservative management were also recorded.

The primary outcome was the type of injuries sustained and injuries were divided by ICD-9 code into the following categories:

- Traumatic brain injury (TBI)

- Skull fracture

- Facial fractures

- Abdominal injury

- Spine fractures

- Upper extremity fracture

- Thoracic injury

- Pelvic fracture

- Hip fracture

- Lower extremity fracture.

The secondary outcome includes mortality/discharge. Data were collected according to predetermined proforma.

\subsection{Research instruments}

Pre-tested proforma was used to collect information bedside after clinical examination and by going through the patient charts. One research assistant accomplished by filling the admitting part of the questionnaire at casualty and confirmed by the author.

\subsection{Data collection management and analysis}

Data collection was done through a structured proforma as described above at the Emergency Department and in the ward. After admission, these patients were monitored until death/discharge and the relevant data was entered accordingly. This was done with assistance by pre-trained admitting staff and assisted by other doctors in the ward. The filled proforma were examined and the data was then systematically compiled in a master sheet using Microsoft Excel Program. All the variables and parameters were then subjected to statistical analysis.

\subsection{Statistical Analysis}

The data were analysed using PASW 18.0 Software; formerly known as SPSS 18.0 Software. The statistical analysis for comparative assessment will include, use of Student's t-test (for continuous scale data) and Pearson's ChiSquare test with Yates correction for categorical variables. Logistic regression analysis was also carried out to identify those factors independently affecting a certain outcome.

\subsection{Ethical consideration}

Permission to carry out the study was granted by MUHS research ethical committee. Additionally, informed consent was requested from the participants In line with consent, participants have explained the nature and purpose of the study.

\subsection{Results}

The results obtained from a comparative cross sectional study conducted on injury and trauma, mortality, morbidity in geriatric and non-geriatric patients admitted in a tertiary care trauma centre in central India is outlined below. The demographic profile of the participants in relation to the age distribution showed a male sex preponderance in both the population groups. Among non-geriatric patients, $62.7 \%$ and $52.6 \%$ were male patients, $37.3 \%$ and $47 \%$ were female patients respectively among geriatric and non-geriatric trauma patients. The geriatric population group showed a clear male preponderance with males making up $62.7 \%$ of the study group. 
The age distribution in the geriatric population group affected by injury and trauma ranged from 65-89 years. The maximum number of fatalities occurred in 65-69 age group while the 85-89 year remains the least affected. Mean age from this study cohort was 72 years. The age distribution in the non-geriatric study population ranged from 18 to 65 years. The age group of 18-27 years had the maximum number of fatality cases with the mean age in the non-geriatric cohort was found to be 39 years.

\begin{tabular}{|l|l|l|l|}
\hline Admission Demographics & Geriatric Population & Non-geriatric Population & P-value \\
\hline $\begin{array}{l}\text { Mean Systolic Blood Pressure (mm } \\
\mathrm{Hg} \text { ) }\end{array}$ & $130 \pm 23.3$ & $117 \pm 21.8$ & $\begin{array}{l}\text { ' } \mathrm{t} \text { ' ratio }=6.895, \\
\mathrm{P}<0.01\end{array}$ \\
\hline $\begin{array}{l}\text { Mean Diastolic Blood Pressure } \\
\text { mm Hg) }\end{array}$ & $81.4 \pm 10.4$ & $75.8 \pm 12.9$ & $\begin{array}{l}\text { ' } \mathrm{t} \text { ' ratio }=5.622, \\
\mathrm{P}<0.01\end{array}$ \\
\hline Mean Pulse Rate (beats per minute) & $90 \pm 14.2$ & $96 \pm 16.8$ & $\begin{array}{l}\text { ' } \mathrm{t} \text { ' ratio }=4.716, \\
\mathrm{P}<0.01\end{array}$ \\
\hline GCS </=8(\%) & $36 \%$ & $35.3 \%$ & $\begin{array}{l}\mathrm{z}=0.170, \\
\mathrm{P}=0.865 \text { (NS) }\end{array}$ \\
\hline
\end{tabular}

Vital parameters such as mean systolic and diastolic blood pressure, mean pulse rate and the number of patients with a Glasgow Coma Score were recorded in both the study (Table 1). These parameters represent the baseline vital signs with which both the populations present to the trauma care centre. Further, these parameters signify the derangements in the physiology secondary to the traumatic event in both populations.

Table 1. Vital parameters in geriatric and non-geriatric population on admission

The geriatric trauma population had a higher mean systolic blood pressure $(130 \mathrm{~mm} \mathrm{Hg})$ compared to the non-geriatric counterparts who showed a mean of (117 $\mathrm{mm} \mathrm{Hg})$. Similarly, the mean diastolic blood pressure in the geriatric age group was relatively higher in the non-geriatric population. The mean pulse rate in the geriatric group was lower compared to the nongeriatric group with a mean of $90 \pm 14.2$ and $96 \pm 16.8$ bpm respectively. Glasgow Coma Scale (GCS) is a neurological scale that aims to give a reliable and objective method of recording the state of a person's consciousness for initial as well as subsequent assessment. A GCS of $>/=8$ is classified as severe brain injury. A shown in Table 1, 36\% of patients showed GCS score $<8$ in both geriatric and non-geriatric patients.

Mechanisms of injury sustained by the participants from both the cohorts i.e. geriatric and non-geriatric populations is presented in Table 2. It is evident that Falls which include both Ground level falls (GLF) and Fall from height ( $>2$ metres) contributed to the largest number of cases in the geriatric population amounting to $55.4 \%$ cases out of all the cases. The next most common cause for trauma in the geriatric population was Road traffic accidents amounting to $34.3 \%$ of the cases. The non-geriatric population showcased a different trend wherein, road traffic accidents contributed to the highest number of cases of $171(57 \%)$. In contrast, the ground level falls had the least number of cases of $14(4.7 \%)$ in this study population. Falls (ground level falls + falls from height) contributed to $19.7 \%$ of all the causes in the non-geriatric population.

\begin{tabular}{|l|l|l|l|}
\hline \multicolumn{1}{|c|}{ Mechanism } & Geriatric Population $(\mathrm{n}=300)$ & Non-geriatric Population $(\mathrm{n}=300)$ & $\mathrm{P}$ value \\
\hline Ground level falls & $48.7 \%$ & $4.7 \%$ & $\mathrm{P}<0.05$ \\
\hline Falls from Height & $6.7 \%$ & $15 \%$ & $\mathrm{P}<0.05$ \\
\hline Road Traffic Accidents & $34.3 \%$ & $57 \%$ & $\mathrm{P}<0.05$ \\
\hline Assaults & $7.7 \%$ & $15.3 \%$ & $\mathrm{P}<0.05$ \\
\hline Others & $2.6 \%$ & $8 \%$ & $\mathrm{P}<0.05$ \\
\hline
\end{tabular}

Table 2. Mechanisms of Injury in Geriatric and Non-geriatric Trauma Patients

Data on the injuries sustained by both the study cohorts in terms of the different body regions are presented in Table 3. These different body regions have an individual abbreviated injury score. The highest AIS scores 3 out of the total 6 regions are squared and summed to give to consolidated Injury severity score (ISS). Thus, both the geriatric and non-

\begin{tabular}{|c|c|c|c|c|}
\hline & Injury Score & Geriatric Population & $\begin{array}{l}\text { Non-geriatric } \\
\text { Population }\end{array}$ & $\mathrm{P}$ - value \\
\hline \multirow{2}{*}{ ISS } & ISS $>/=16$ & 252 & 254 & \multirow{2}{*}{$\begin{array}{l}\mathrm{Z}=0.22, \mathrm{P}=0.825 \\
\text { Not Significant }\end{array}$} \\
\hline & ISS $<16$ & 48 & 46 & \\
\hline \multirow{2}{*}{ Head AIS } & Head AIS $>/=3$ & 213 & 193 & \multirow{2}{*}{$\begin{array}{l}Z=1.745, P=0.080 \\
\text { Not Significant }\end{array}$} \\
\hline & Head AIS <3 & 87 & 107 & \\
\hline \multirow{2}{*}{ Face AIS } & Face AIS $>/=3$ & 33 & 21 & \multirow{2}{*}{$\begin{array}{l}\mathrm{Z}=1.7118, \mathrm{P}=0.08726 \\
\text { Not Significant }\end{array}$} \\
\hline & Face AIS <3 & 267 & 279 & \\
\hline \multirow{2}{*}{ Neck AIS } & Neck AIS $>/=3$ & 4 & 15 & \multirow{2}{*}{$\begin{array}{l}Z=-2.5645 \\
P=0.01046\end{array}$} \\
\hline & Neck AIS <3 & 296 & 285 & \\
\hline
\end{tabular}

geriatric study populations had comparable Injury Severity Scores of greater than or equal to 16 which signifies a severe overall injury. The head region was most consistently and maximally injured in both the study populations. AIS $>/=3$ is defined as a severe injury to the head. 


\begin{tabular}{|c|c|c|c|c|}
\hline \multirow{2}{*}{ Thorax } & Thorax $>/=3$ & 72 & 100 & \multirow{2}{*}{$\mathrm{Z}=2.5278, \mathrm{P}=0.0114$} \\
\hline & Thorax $<$ & 228 & 200 & \\
\hline \multirow{2}{*}{ Abdomen } & Abdomen $>/=3$ & 48 & 105 & \multirow{2}{*}{$\mathrm{Z}=-5.3389, \mathrm{P}=0.00001$} \\
\hline & Abdomen < & 252 & 195 & \\
\hline \multirow{2}{*}{ Extremities } & Extremities $>/=3$ & 135 & 114 & \multirow{2}{*}{$\begin{array}{l}Z=1.74, P=0.08186 \\
\text { Not Significant }\end{array}$} \\
\hline & Extremities <3 & 165 & 186 & \\
\hline \multirow{2}{*}{ External } & External $>/=3$ & 18 & 13 & \multirow{2}{*}{$\begin{array}{l}\mathrm{Z}=0.9222, \mathrm{P}=0.35758 \\
\text { Not Significant }\end{array}$} \\
\hline & External <3 & 282 & 287 & \\
\hline
\end{tabular}

Table 3. Injury Severity Scores (ISS) and Abbreviated Injury Score (AIS) for each body region in Geriatric and Non-geriatric trauma patients

The non-geriatric cohort had AIS $>/=3$ of head injury. The next highest contributor to morbidity in the non-geriatric cohort was also severe extremity injury with Extremity AIS $>/=3$. The non-geriatric population was observed to have sustained a much higher proportion of severe thoracic (100 vs 72 ) and abdominal injuries (105 vs 48) as compared to the geriatric counterparts, both of which were statistically significant.

Comorbidity profiles of geriatric and non-geriatric trauma populations are presented in Table 4 . The geriatric study group had a significantly higher number of a wide range of comorbidities with many patients having more than 1 comorbidity simultaneously. Hypertension was the most common comorbidity noted amongst both the study groups although, the geriatric

study group had more than twice the number of cases with hypertension compared to the non-geriatric population i.e. $50 \%$ and $24 \%$ respectively. Cerebrovascular disease was noted amongst $25 \%$ and $17 \%$ of the geriatric and non-geriatric trauma populations respectively with the geriatric cohort showing a higher incidence. $27 \%$ of the geriatric study population was diabetic as compared to $24 \%$ of the non-geriatric population who also had diabetes mellitus. The diminished vision was noted in $30 \%$ of the geriatric trauma patients as opposed to just $13 \%$ of the non-geriatric patients having the same complaints. The diminished hearing was also primarily noted in the geriatric population with up to $28 \%$ of them having the above comorbidity as opposed to just $6 \%$ of the non-geriatric population having diminished vision.

\begin{tabular}{|l|l|l|l|}
\hline Comorbidity & $\begin{array}{l}\text { Geriatric Population } \\
(\%)\end{array}$ & $\begin{array}{l}\text { Non-geriatric } \\
\text { Population }(\%)\end{array}$ & P value \\
\hline Hypertension & $151(50 \%)$ & $73(24 \%)$ & Z=6.583, $<<0.0001$ \\
\hline Ischaemic Heart Disease & $40(13 \%)$ & $28(9 \%)$ & $\begin{array}{l}\text { Z=1.5454, }=0.12114 \\
\text { Not Significant }\end{array}$ \\
\hline Cerebrovascular disease & $75(25 \%)$ & $52(17 \%)$ & Z=2.2986, $<0.02144$ \\
\hline Chronic obstructive Pulmonary Disorder & $18(6 \%)$ & $28(9 \%)$ & $\begin{array}{l}\text { Z=-1.5344, } \mathrm{p}=0.12602 \\
\text { Not Significant }\end{array}$ \\
\hline Diabetes Mellitus & $81(27 \%)$ & $72(24 \%)$ & $\begin{array}{l}\text { Z=0.843, }=0.4009 \\
\text { Not Significant }\end{array}$ \\
\hline Chronic Renal Failure & $22(7 \%)$ & $21(7 \%)$ & $\begin{array}{l}\text { Z=0.1583, }=0.87288 \\
\text { Not Significant }\end{array}$ \\
\hline Diminished Vision & $89(30 \%)$ & $40(13 \%)$ & Z=4.8693, p<0.00001 \\
\hline Diminished Hearing & $83(28 \%)$ & $19(6 \%)$ & $Z=6.9557, \mathrm{p}<0.00001$ \\
\hline
\end{tabular}

Table 4. Comorbidities in Non-geriatric and Geriatric Trauma Patients

Various injury patterns noted in both the study populations have been stratified by the various mechanisms of injury is presented in Table 5. Falls contributed to the highest number of cases $(55 \%)$ in the geriatric population followed by RTA $(34 \%)$ as the next major cause for trauma.

\begin{tabular}{|c|c|c|c|c|}
\hline Mechanism of Injury & Injury & Geriatric & Non-geriatric & P- Value \\
\hline \multirow{7}{*}{$\begin{array}{l}\text { Falls } \\
\mathrm{G}=166 \\
\mathrm{NG}=59\end{array}$} & Head & $128(77 \%)$ & $35(59 \%)$ & $\mathrm{Z}=8.5, \mathrm{p}<0.00001$ \\
\hline & Face & $19(11 \%)$ & $2(3 \%)$ & $\mathrm{Z}=3.8, \mathrm{p}<0.00016$ \\
\hline & Neck & $0(0 \%)$ & $5(8 \%)$ & $\mathrm{Z}=-2.2, \mathrm{p}<0.02$ \\
\hline & Thorax & $28(17 \%)$ & $27(46 \%)$ & $\begin{array}{l}\mathrm{Z}=-0.1, \mathrm{p}=0.88 \\
\text { Not Significant }\end{array}$ \\
\hline & Abdomen & $15(9 \%)$ & $27(46 \%)$ & $\begin{array}{l}\mathrm{Z}=--1.9, \mathrm{p}<0.05 \\
\text { Not Significant }\end{array}$ \\
\hline & Extremity & $107(64 \%)$ & $33(56 \%)$ & $\mathrm{Z}=7.1, \mathrm{p}<0.00001$ \\
\hline & External & $33(20 \%)$ & $6(10 \%)$ & $\mathrm{Z}=4.5, \mathrm{p}<0.00001$ \\
\hline \multirow{3}{*}{$\begin{array}{l}\text { Ground level Falls } \\
\mathrm{G}=145 \\
\mathrm{NG}=14\end{array}$} & Head & $116(80 \%)$ & $6(43 \%)$ & $\mathrm{Z}=11.2, \mathrm{p}<0.00001$ \\
\hline & Face & $18(12 \%)$ & $0(0 \%)$ & $\mathrm{Z}=4.3, \mathrm{p}<0.00001$ \\
\hline & Neck & $0(0 \%)$ & $1(7 \%)$ & $\begin{array}{l}\mathrm{Z}=-1.0, \mathrm{p}=0.3 \\
\text { Not Significant }\end{array}$ \\
\hline
\end{tabular}

Amongst the falls, Ground level fall has been the highest casualty at $87 \%$ as compared to fall from height (> 2metres) contributing $13 \%$ towards the total number of falls. 


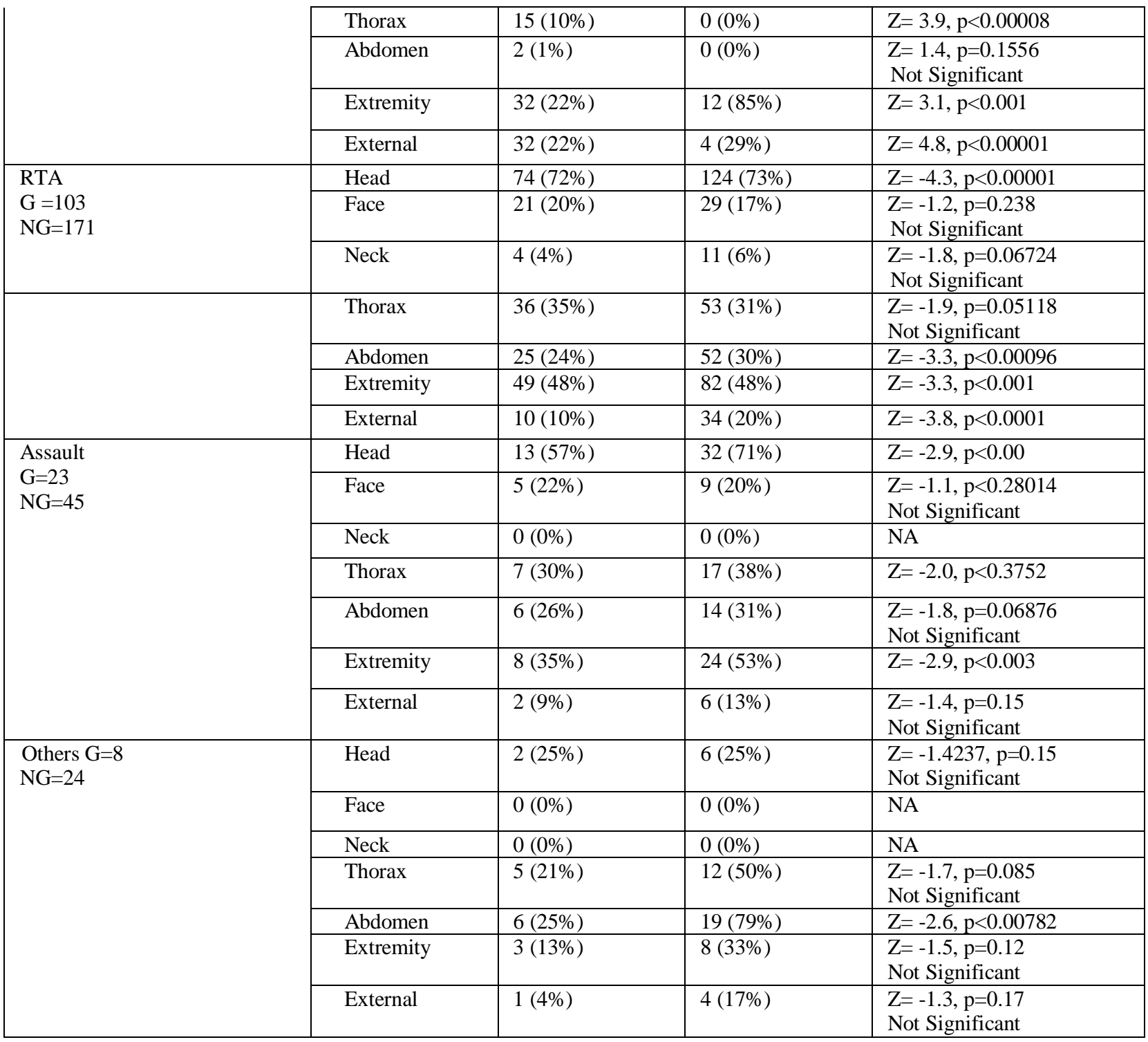

Table 5. Injury Patterns for Geriatric and Non-geriatric Trauma Patients Stratified by Mechanism of Injury

The head and extremities were most often injured in the geriatric population sustaining falls with $77 \%$ and $64 \%$ of them showing the above the two injuries respectively. The next major mechanism responsible for trauma in the geriatric age group is Road traffic accidents (RTA) with $34 \%$ of the population having sustained RTA. The head, extremities and thorax were once again most often injured at $72 \%, 48 \%$ and $35 \%$ respectively. In the non-geriatric population, RTA was the major cause of trauma responsible for $57 \%$ of the casualties with the head, extremities, thorax and abdominal injuries accounting for the injury patterns in the descending order.

\begin{tabular}{|l|l|l|l|}
\hline Intervention & $\begin{array}{l}\text { Geriatric Population } \\
(\mathrm{n}=300)\end{array}$ & $\begin{array}{l}\text { Non-geriatric Population } \\
(\mathrm{n}=300)\end{array}$ & P-value \\
\hline Operative Intervention (\%) & $136(45.3 \%)$ & $170(56.7 \%)$ & $\begin{array}{l}\mathrm{Z}=-2.7, \\
\mathrm{p}<0.005\end{array}$ \\
\hline Conservative Management (\%) & $164(54.7 \%)$ & $130(43.3 \%)$ & $\begin{array}{l}\mathrm{Z}= \\
\mathrm{p}<0.005\end{array}$ \\
\hline
\end{tabular}

Table 6. Comparison between the geriatric and non-geriatric populations in terms of operative interventions vs non-operative interventions
Table 6. Illustrates a comparison between the geriatric and non-geriatric trauma populations who underwent operative interventions and conservative management. It is evident that the geriatric population had a lower percentage of patients who underwent an operative intervention as compared to the non-geriatric population $(45.3 \%$ vs $56.7 \%)$. Similarly, the geriatric population group had a higher rate of conservatively managed patients as compared to the non-geriatric population $(54.7 \%$ vs 43.3\%). Both the findings were statistically significant.

\section{(Conservative management).}


The different operative interventions underwent by the geriatric and nongeriatric trauma populations is presented in Table 7. The geriatric population had the maximum number of patients who underwent Orthopaedic and spine surgeries $(44.9 \%)$ followed by Intercostal drain placements $(34.6 \%)$, Craniotomies $(22.8 \%)$ and Laparotomies $(14 \%)$ in the decreasing order. The non-geriatric population had the maximum number of Craniotomies (40\%) followed by Intercostal drain placements (33.5\%), laparotomies (23\%) and orthopedic and spinal surgeries (15.9\%)

\begin{tabular}{|l|l|l|l|}
\hline Operative Intervention & $\begin{array}{l}\text { Geriatric } \\
\text { Population }(\%) \\
(\mathrm{n}=136 / 300)\end{array}$ & $\begin{array}{l}\text { Non-geriatric } \\
\text { Population }(\%) \\
(\mathrm{n}=170 / 300)\end{array}$ & $\mathrm{P}$-value \\
\hline Craniotomy & $31(22.8 \%)$ & $68(40 \%)$ & $\mathrm{Z}=-4.0, \mathrm{p}<0.00001$ \\
\hline Laparotomy & $19(14.0 \%)$ & $39(23.0 \%)$ & $\mathrm{Z}=-2.7, \mathrm{p}<0.00578$ \\
\hline Orthopaedic and Spine Surgeries & $61(44.9 \%)$ & $27(15.9 \%)$ & $\mathrm{Z}=3.9, \mathrm{p}<0.00008$ \\
\hline Intercostal Drain Placements & $47(34.6 \%)$ & $57(33.5 \%)$ & Not Significant \\
\hline Others & $0(0 \%)$ & $3(1.8 \%)$ & $\begin{array}{l}\mathrm{Z}=-1.7, \mathrm{p}=0.08 \\
\text { Not Significant }\end{array}$ \\
\hline
\end{tabular}

Table 7.Comparison of the different operative interventions underwent by the geriatric and non-geriatric trauma populations.

The geriatric population had a significantly higher crude mortality rate at $39.3 \%$ as compared to the non-geriatric population (Table 8). Falls especially ground level falls were responsible for the maximum number of mortalities (58.5\%) among all mechanisms of injury followed by RTA

\begin{tabular}{|l|l|l|l|}
\hline Mortality rate & $\begin{array}{l}\text { Geriatric Population } \\
(\mathrm{n}=118)\end{array}$ & $\begin{array}{l}\text { Non-geriatric Population } \\
(\mathrm{n}=79)\end{array}$ & $\mathrm{P}$-value \\
\hline Crude Mortality (\%) & $39.3 \%$ & $26.3 \%$ & $\mathrm{Z}=3.39 \mathrm{P}<0.01$ \\
\hline $\begin{array}{l}\text { Ground level fall + } \\
\text { Fall from Height }\end{array}$ & 75 & 15 & $\mathrm{Z}=6.8, \mathrm{p}<0.00001$ \\
\hline Ground level Falls & $58.5 \%$ & $2.5 \%$ & $\mathrm{Z}=10.1, \mathrm{p}<0.00001$ \\
\hline Falls from Height & $5.1 \%$ & $16.5 \%$ & $\mathrm{Z}=-4.1, \mathrm{p}<0.00001$ \\
\hline RTA & $33.1 \%$ & $64.6 \%$ & $\mathrm{Z}=-7.6, \mathrm{p}<0.00001$ \\
\hline Assault & $1.7 \%$ & $6.3 \%$ & $\mathrm{Z}=-2.9, \mathrm{p}<0.0035$ \\
\hline Others & $1.6 \%$ & $10.1 \%$ & $\mathrm{Z}=-2.9, \mathrm{p}<0.0035$ \\
\hline
\end{tabular}

Table 8. Mortality according to the Mechanism of Injury in Geriatric and Non-geriatric populations.

Factors that are independently associated with mortality for the entire population i.e. geriatric and non-geriatric populations is presented with statistical significance in Table 9. These factors have been identified on logistic regression analysis. Odds ratios are used to compare the relative odds of the occurrence of the outcome of interest (e.g. disease or

\begin{tabular}{|l|l|l|l|}
\hline Risk Factor & Odds Ratio & 95\% Confidence interval & P value \\
\hline Admission Physiology & 1.0295 & 0.7371 to 1.4379 & $\mathrm{P}=0.864$ \\
\hline GCS $</=8$ & 11.7424 & 6.6153 to 20.8432 & $\mathrm{P}<0.0001$ \\
\hline Mechanism & 0.3944 & 0.2835 to 0.5488 & $\mathrm{P}<0.0001$ \\
\hline Ground level Falls & 1.3573 & 0.9627 to 1.9137 & $\mathrm{P}=0.0813$ \\
\hline Road Traffic Accidents & 0.6316 & 0.4417 to 0.9030 & $\mathrm{P}=0.00118$ \\
\hline Injury Severity & 0.2397 to 0.5221 & $\mathrm{P}<0.0001$ \\
\hline Head AIS $>/=3$ & 0.3537 & 0.9638 to 1.8489 & $\mathrm{P}=0.0822$ \\
\hline Thorax $>/=3$ & 1.3349 & \\
\hline Abdomen $>/=3$ & &
\end{tabular}

disorder), given exposure to the variable of interest (e.g. health characteristic, aspect of medical history). The odds ratio can also be used to determine whether exposure is a risk factor for a particular outcome and to compare the magnitude of various risk factors for that outcome.

$(33.1 \%)$ in the geriatric trauma population. Road traffic accidents were the cause of the maximum number of mortalities (64.6\%) amongst the non-geriatric population in the present study. fewer number of craniotomies compared to the non-geriatric population
while a significantly higher number of orthopedic and spinal surgeries fewer number of craniotomies compared to the non-geriatric population
while a significantly higher number of orthopedic and spinal surgeries were performed in the geriatric age group as compared to the nongeriatric population. The non-geriatric population had a higher number of craniotomies performed as compared to the geriatric age group.

in the descending order. It can be deduced that the geriatric population,

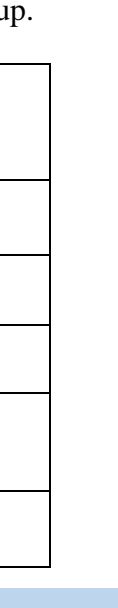




\begin{tabular}{|l|l|l|l|}
\hline Hypertension & 3.1513 & 2.262 to 4.4609 & $\mathrm{P}<0.0001$ \\
\hline Cerebrovascular disease & 1.5897 & 1.0688 to 2.3647 & $\mathrm{P}=0.0221$ \\
\hline Diabetes mellitus & 1.1712 & 0.8109 to 1.6917 & $\mathrm{P}=0.3994$ \\
\hline Diminished Vision & 2.7417 & 1.8105 to 4.1518 & $\mathrm{P}<0.0001$ \\
\hline Diminished Hearing & 5.6568 & 3.3329 to 9.6010 & $\mathrm{P}<0.0001$ \\
\hline
\end{tabular}

Odds ration=1 Exposure does not affect odds outcome.

Odds ratio $>1$ Exposure associated with higher odds outcome.

Odds ratio $<1$ Exposure associated with lower odds outcome.

\section{Table 9. Factors Associated with Mortality for the Entire Population Identified on Logistic Regression.}

It is clearly evident that Ground level falls (OR - 11.742 and CI - 6.6153 to 20.8432) are independently associated with mortality for the entire population and in the geriatric population ground level falls are significantly high compared to the non-geriatric group. Head (OR - 1.357 and CI - 0.9627 to 1.9137 ) and extremity injuries (OR - 1.3349 and CI 0.9638 to 1.8489 ) are common in both population groups secondary to a traumatic event and thus, also independently are associated with mortality. Amongst, the comorbidities, it is clear that hypertension (OR 3.1513 and CI - 2.262 to 4.4609), diminished vision (OR - 2.7417 and CI - 1.8105 to 4.1518 ) and diminished hearing (OR - 5.6568 and CI - 3.3329 to 9.6010 ) are other major contributors for mortality.

\subsection{Discussion}

A comprehensive comparative cross-sectional study on mortality and morbidity and the factors affecting the trauma in geriatric and nongeriatric patients was conducted in a tertiary care and trauma centre in central India. An in-depth evaluation of comorbidities, mechanism of injury, injury pattern and preventive interventions in 300 geriatric population and non-geriatric trauma patients each were undertaken in this study after meeting the pre-decided inclusion criteria. These subjects were then evaluated according to the various parameters and the results obtained were subsequently analyzed.

Demographic details of both the cohorts were collected and analyzed. In our study, there was a significant male preponderance $(62.7 \%)$ in the geriatric whereas the non-geriatric population showed a marginal increase in the males over the females. In the geriatric trauma population, there was a clear male predilection in every age distribution group. A retrospective analysis of the Trauma Audit and Research Network (TARN) database, an ongoing national study of trauma epidemiology in the United Kingdom. reported a significantly greater proportion of female patients $(42 \%)$ in the geriatric group. This could be attributed to the demographic differences between the two regions and populations [10]. The geriatric age range as decided by the inclusion criteria in this study was found to be between 65-89 years and 18-27 years among the nongeriatric group. The mean age amongst this cohort was 72 and 39 years respectively and a similar mean age group of 75 years was reported [10]. Adults between the ages of 18-30 years in this study were found to be more prone to traumatic injuries due to their risk behavior which is common in young adults.

From the initial time of injury, the overall experience of an elderly person who sustains a traumatic injury can be very different from that of a younger patient with trauma, and special consideration should be given to proper triage and treatment of the geriatric patient with trauma. Once a geriatric patient arrives at a trauma centre, evaluation of the geriatric patient should proceed as is appropriate for their advancing age. Vital signs and physical examination can be deceptive in these patients, who may exhibit examination characteristics very different from those of younger patients. Although the ATLS protocol should be followed for geriatric patients just as it is for younger patients, there are some differences in the normal physiology of elderly patients that will make their evaluation and treatment more challenging. Elderly patients also subjectively report less pain for the same severity of injury than do their younger counterparts [11].

Certain vital parameters such as mean systolic blood pressure, mean pulse rate and GCS were recorded on admission in both the study populations, The geriatric population showed a much higher systolic blood pressure on admission at a mean of $130 \mathrm{~mm}$ of $\mathrm{Hg}$ across all the cases as compared to the non-geriatric age group which had a mean of $117 \mathrm{~mm}$ of $\mathrm{Hg}$ (Table 4). These observations suggest that the geriatric cardiovascular physiology who have higher baseline blood pressures and ejection fractions, lower left ventricular end-diastolic volumes, stroke volumes, and cardiac outputs compared to younger populations [12]. These findings in our study are in accordance with the findings of earlier reports where the geriatric trauma population also showed a higher mean systolic blood pressure, lower mean pulse rates as compared to the non-geriatric counterparts despite having a higher mean systolic blood pressure across all mechanisms of injury [13].

The physiology of aging affects every organ system in the geriatric person but the effects of this is most pronounced on the cardiovascular system and may significantly impact the care of the elderly trauma patient. These changes are mostly because of fundamental changes in the arteries that lead to decreased compliance, stiffness, and eventual hypertension [14]. The geriatric patients at baseline have systolic and diastolic dysfunction ${ }^{43}$ and a blunted response to adrenergic stimulation that may limit vasoconstriction $^{42,44}$ and the ability to mount a tachycardic response $[15,16,17]$ which is frequently magnified by the chronic use of betablocking agents in this population. These physiologic changes also lead to cardiovascular comorbidities which are predominantly found in the elderly population as evidenced by the cardiovascular comorbidity rates found in the elderly in our study i.e. hypertension (50\% vs 24\%), ischaemic heart disease (13\% vs $9 \%$ ) and cerebrovascular disease $(25 \%$ vs $17 \%$ ).

Glasgow Coma Scale (GCS) scoring can be particularly difficult in the geriatric patient, who may have pre-existing cognitive deficits, hearing impairment, or other factors that can confound these examinations [18]. The clinical neurologic examination has also been shown to be unreliable in detecting significant hemorrhage in patients with minor head trauma [19]. Thus, a low threshold of reliability in ancillary studies on the geriatric patient with trauma has to be emphasized. In our study, the geriatric population had comparable rates of GCS $</=8$ with the nongeriatric population with head injuries being the most common injury pattern across the various mechanisms causing injury. Despite this, the geriatric population has a higher crude mortality rate compared to their non-geriatric counterparts which underline that there are certain other factors responsible for this. The GCS is, therefore, an unreliable clinical tools and rapid and repeated use of computed tomography (CT) of the head becomes the essential means of identifying increased intracranial pressure [20]. 
Several factors place the geriatric population at risk for traumatic events, and subsequent delayed recovery from trauma. Conditions that predispose patients to incur trauma are seen in higher prevalence in the elderly population. Weakness or chronic illnesses can lead to an increased rate of falls or other accidents in these patients. Loss of visual acuity, balance and gait instability, slowed reaction times, and cognitive impairments are also important disabilities that may lead to an increased incidence of traumatic events in the elderly. Often these issues are not recognized before the trauma, and cognitive dysfunction can be seen up to $35 \%$ of the time in the geriatric visitor to the emergency department but is only recognized $6 \%$ of the time [21]. Trauma itself is also an increased risk factor for future traumas, with elderly patients who have sustained trauma in the past being 3 times more likely to have a future traumatic event [21]. Owing to the constellation of problems seen in the elderly, prevention of geriatric trauma should be addressed by all clinicians caring for a geriatric patient.

Falls account for nearly three-quarters of all traumas in the geriatric population, with motor vehicle accidents accounting for nearly all the remaining $25 \%$ of injuries. Penetrating trauma and other mechanisms make up only $4 \%$ of total trauma in the geriatric population [22]. Among the elderly patients, nearly $90 \%$ experienced simple falls, such as falls from standing. Despite being simple mechanisms, the multiple comorbidities in the elderly population, along with the need for rehabilitation, make falls a significant medical and economic event in the life of these patients. Falls associated with blunt cerebral injury and long bone fractures lead to the greatest morbidity and mortality [23]. Ground level fall with head injuries coming in at $(80 \%)$ and extremity injuries at (22\%). With these injury patterns, it is not surprising that mortality was higher in geriatric patients after falls compared to the non-geriatric counterparts (25\% vs 5\%). Although ground level falls are a low-energy mechanism and may seem innocuous, mortality was higher in this series of geriatric patients (23\% vs $0 \%$ ). However, in the non-geriatric population, the most mechanism of injury was RTA (57\%), with head injury $(72 \%)$ followed by extremity injuries at $48 \%$. Our findings are similar and comparable to ground level falls, mortality among older, aged patients reported elsewhere $[24,25]$. In our study, deaths due to RTA in the geriatric group was $33 \%$ while RTA was the cause of death of $64.5 \%$ in the non-geriatric age group.

It should also be noted that $35 \%$ of the injuries that occurred secondary to RTA in the geriatric group were thoracic injuries. It has been well established that elderly patients with rib fractures are at increased risk for adverse outcomes including pneumonia, prolonged ICU stay and ventilator days, and increased mortality [26-28]. About one-quarter of all elderly victims of motor vehicle accidents sustain chest trauma, such as flail chest and rib fractures, which can complicate pre-existing cardiopulmonary disease and lead to pneumonia or respiratory failure, complications which are known to have particularly high morbidity and mortality $[29,30]$. RTA being high energy and velocity injuries contribute to much more varied and severe injuries in the elderly who have already compromised physiologies and thus, are unable to cope with the trauma.

Traumatic brain injury is quite common in geriatric patients after both falls and RTA and so, the trauma surgeon must realize the potentially lethal combination of TBI and older age. Geriatric trauma patients should receive liberal CT scanning for several reasons. With age comes brain atrophy that causes stretching of bridging veins and an increased risk of subdural hematoma [31]. Clinical decision-making tools commonly used to evaluate younger trauma patients should not be applied to older trauma patients [31]. Further, the neurological exam is unreliable in elderly patients and may miss significant TBI.

Injury Severity Score is an important method for describing patients with multiple injuries and evaluating emergency care. For a trauma centre intending to perform an effective review of their service, as well as for the scientific study of trauma, it is important to have an accurate benchmark of mortality risk. This benchmark serves as a predictor of mortality or "expected" outcome for any patient presenting with certain injuries. Trauma and Injury Severity Score (TRISS) utilizes the patient's age, type of injury, Revised Trauma Score (RTS), and the Injury Severity Score to estimate the probability of survival. It considers the patient's physiological injury, a physiological response and anatomic injury [32]. The Injury Severity Score (ISS), supplies the anatomic index for TRISS, and has been a standard tool for three decades. A major trauma (or polytrauma) is defined as the Injury Severity Score is greater than 15 $[33,34]$. In our study, both the geriatric and non-geriatric populations had comparable ISS $>/=16$ suggestive of major and severe trauma (252 vs 254). The geriatric trauma population had a higher crude mortality rate compared to the non-geriatric population even though both of them had similar ISS rates of 16 and above (39.3\% vs $26.3 \%$ ) which highlights that there are certain factors which are intrinsic to the geriatric group responsible for the higher mortality rate.

Co-morbidities are present in both the geriatric and non-geriatric populations but the relatively higher proportion of the various comorbidities in the geriatric population susceptible to the morbid nature of traumatic injuries. It is not uncommon to find multiple comorbidities in the geriatric population. Our study emphasized the fact that a large proportion of the geriatric population is hypertensive $(50 \%)$, diabetic $(27 \%)$. About $25 \%$ of them had sustained at least one episode of cerebrovascular accident, about $30 \%$ of them had diminished vision and $28 \%$ of them had diminished hearing respectively. These comorbidities have a significant impact on the response to a traumatic event in the geriatric population, who are already less healthy as compared to their younger counterparts. It is evident that the comorbidity profile in the geriatric age group is an important and independent risk factor for higher morbidity and mortality.

In our study, both the geriatric and non-geriatric trauma populations were subjected to operative interventions or otherwise afforded conservative management. About $45.3 \%$ of the geriatric population underwent various operative interventions while the rest of them were afforded conservative management. It should also be noted that the crude mortality rate of the geriatric age group is also higher compared to the non-geriatric population $(39.3 \%$ vs $26.3 \%)$. Age is an independent risk factor for mortality in the geriatric age group and thus, a major operative intervention in the setting of an already compromised geriatric physiology with a superadded traumatic event is a major risk factor for mortality in such cases. Similarly, the majority of cases in the geriatric population were secondary to ground level falls leading to mainly head and extremity injuries as previously illustrated. It is interesting to note that the geriatric age group had a higher proportion of orthopedic and spinal surgeries as compared to craniotomies $(22.8 \%$ vs $44.9 \%)$. A severe head injury is more life threatening is afforded priority in the case of a poly-trauma and thus, decides the line of management in such patients. It was observed that severe head injuries in the geriatric population $(\mathrm{GCS}</=8)$ were, more often than not, managed conservatively.

The non-geriatric population had a higher rate of undergoing operative interventions compared to the geriatric counterparts (56\% vs $45.3 \%)$ with a crude mortality rate in the non-geriatric age group being $26.3 \%$. This group had a higher percentage of Craniotomies and Laparotomies performed compared to the geriatric trauma population while the percentages of immediate lifesaving interventions like intercostal drain insertions were comparable in both groups. It is also noted that the geriatric trauma population group was afforded conservative management more commonly than operative interventional procedures. This could be attributed to the fact that a major operative intervention is a major risk factor for morbidity and mortality in geriatric trauma patients. An operative intervention has inherent risk factors including both surgical 
and anesthetic complications. However, it affects the geriatric population more than the non-geriatric population considering the already compromised physiology secondary to the process of aging.

In conclusion, elderly patients with trauma must be triaged, evaluated, and treated differently from their younger counterparts. Older adults have unique physiologic and structural differences that leave them at an increased risk of mortality even during minor trauma. Early recognition of these differences can lead to a better mortality rate and a more productive recovery after trauma along with the formulation of protocols specifically tailored for geriatric trauma patients.

\subsection{References}

1. United Nations, Department of Economic and Social Affairs, Population Division (2015). World Population Ageing 2015 (ST/ESA/SER.A/390).

2. Economic times Apr 2019. https://economictimes.indiatimes.com/news/

3. Adams SD, Holcomb JB. (2015). Geriatric trauma. Current Opinion Critical Care; 21: 520-526

4. Banks SE, Lewis MC. (2013). Trauma in the elderly: considerations for anesthetic management. Anesthesiology Clinics; 31: 127-139

5. Keller JM, Sciadini MF, Sinclair E, O’Toole RV. (2012). Geriatric trauma: demographics, injuries, and mortality. Journal Orthopaedics and Trauma; 26: e161-e165

6. Shortt NL, Robinson CM. (2005). Mortality after low-energy fractures in patients aged at least 45 years old. Journal Orthopaedics and Trauma; 19: 396-400

7. Baker SP, Harvey AH. (1985). Fall injuries in the elderly. Clinical Geriatric Medicin; 1:501-512

8. Bina M, Graziano F, Bonino S.(2005). Risky driving and lifestyles in adolescence. Accid Anal Prev

9. Labib N, Nouh T, Winocour S, et al. (2010). Severely injured geriatric population: morbidity, mortality and risk factors. Journal of Trauma; 71: 1908-1914

10. Court-Brown PJ, Pape HC. (2009). Severe and multiple trauma in older patients; incidence and mortality, Injury; 40: 362-367

11. Gibson SJ, Helme RD. (2001). Age-related differences in pain perception and report. Clinical Geriatrics Medicine; 17: 433456

12. Rooke GA. (2003). Cardiovascular aging and anesthetic implications. Journal of Cardiothoracic Vascular Anesthesia; 17:512-523

13. Brown CV, Rix K, Klein AL, Ford B, Teixeira PG, et.al.(2016). Comprehensive Investigation of Comorbidities, Mechanisms, Injury Patterns, and Outcomes in Geriatric Blunt Trauma Patients. American Surgery ; 82(11): 1055-1062

14. Christou DD, Seals DR. (2008). Decreased maximal heart rate with aging is related to reduced \{beta\}-adrenergic responsiveness but is largely explained by a reduction in intrinsic heart rate. Journal of Applied Physiology; 105: 24-29

15. Villella E, Cho SJ. (2015). Effect of aging on the vascular system plus monitoring and support. Surgical Clinics of North America; 95: $37-51$
16. Martin RS, Farrah JP, Chang MC. (2015). Effect of aging on cardiac function plus monitoring and support. Surgical Clinics of North America; 95: 23-35

17. Elliott HL, Sumner DJ, McLean K, et al. (1982). Effect of age on the responsiveness of vascular alpha-adrenoceptors in man. Journal of Cardiovascular Pharmacology; 4: 388-392

18. Zuercher M, Ummenhofer W, Baltussen A, et al. (2009). The use of Glasgow Coma Scale in injury assessment: A critical review. Brain Injury; 23(5): 371-384

19. 19. Mack LR, Chan SB, Silva JC, et al. (2003). The use of head computed tomography in elderly patients sustaining minor head trauma. Journal of Emergency Medicine; 24:157-162

20. Mutch CA, Talbott JF, Gean A.(2016). Imaging Evaluation of Acute Traumatic Brain Injury. Neuro surgery Clinics of North America; 27(4): 409-439

21. Siracuse JJ, Odell DD, Gondek SP, et al. (2012). Health care and socioeconomic impact of falls in the elderly. American Journal of Surgery; 203: 335-338

22. Ayoung-Chee O, McIntyre L, Ebel BE, et al. (2014). Long-term outcomes of ground level falls in the elderly. Journal of Trauma Acute Care Surgery; 76: 498-503

23. Spaniolas K, Cheng JD, Gestring ML, et al. (2010). Ground level falls are associated with significant mortality in elderly patients. Journal of Trauma; 69: 821-825

24. Ayoung-Chee O, McIntyre L, Ebel BE, et al. (2014). Long-term outcomes of ground level falls in the elderly. Journal of Trauma Acute Care Surgery; 76: 498-503

25. Brown CV, Rix K, Klein AL, Ford B, Teixeira PG. (2016). A Comprehensive Investigation of Comorbidities, Mechanisms, Injury Patterns, and Outcomes in Geriatric Blunt Trauma Patients. American Surgeon; 82(11):1055-1062

26. Sharma OP, Oswanski MF, Jolly S, et al. (2008). Perils of rib fractures. American Surgeon; 74:310-314

27. Bulger EM, Arneson MA, Mock CN, et al. (2000). Rib fractures in the elderly. Journal of Trauma; 48:1040-1046

28. Bergeron E, Lavoie A, Clas D, et al. (2003). Elderly trauma patients with rib fractures are at greater risk of death and pneumonia. Journal of Trauma Acute Care Surgery; 54: 478485

29. Lee WY, Cameron PA, Bailey MJ. (2005). Road traffic injuries in the elderly. Emergency Medicine Journal; 23: 42-46

30. Cohen DB, Rinker C, Wilberger JE. (2006). Traumatic brain injury in anti-coagulated patients. Journal of Trauma; 60: 553557

31. Lee KS (2016) Chronic Subdural Hematoma in the Aged, Trauma or Degeneration? Journal of Korean Neurosurgical Society; 59(1): 1-5

32. Calvin HKM, Stephen KHW, George KW, Stephanie NG, Kevin KWW, et.al. (2012). Traumatic Brain Injury in the Elderly: Is it as Bad as we Think? Current Translational Geriatrics Experimental Gerontology Reports; 1(3)

33. Baker SP, O’Neill B, Haddon W Jr. (1974). The Injury Severity Score: a method for describing patients with multiple injuries and evaluation emergency care. Journal of Trauma; 14:187

34. Copes WS, Champion HR, Sacco WJ, Lawnick MM, Keast SL,et.al. (1988). "The Injury Severity Score revisited". Journal of Trauma; 28 (1): 69-77 